\title{
Clipping Alters the Response of Biomass Production to Experimental Warming: A Case Study in an Alpine Meadow on the Tibetan Plateau, China
}

\author{
FU Gang ${ }^{1}$ iD http://orcid.org/oooo-0002-6055-8730; e-mail: fugango9@126.com \\ SUN Wei1 a (D http://orcid.org/oooo-ooo1-5591-4799; e-mail: wsun@igsnrr.ac.cn \\ YU Cheng-Qun' (iD http://orcid.org/oooo-0002-4044-105X; e-mail: yucq@igsnrr.ac.cn

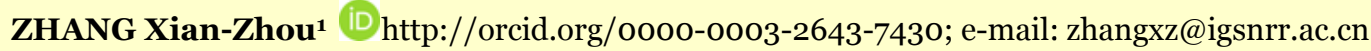 \\ SHEN Zhen-Xi1 iD http://orcid.org/oooo-ooo2-3485-5459; Мe-mail: shenzx@igsnrr.ac.cn \\ LI Yun-Long1,2 iD http://orcid.org/oooo-0002-2203-6843; e-mail: liyunlongwf@163.com \\ YANG Peng-Wan1,2, iD http://orcid.org/oooo-ooo3-1045-5714; e-mail: yangpengwan2012@126.com \\ ZHOU Nan ${ }^{1,2}$ iD http://orcid.org/oooo-0o02-9816-2678; e-mail: zhoun.13s@igsnrr.ac.cn \\ a The author contributed equally to this work \\ 1 Lhasa Plateau Ecosystem Research Station, Key Laboratory of Ecosystem Network Observation and Modeling, \\ Institute of Geographic Sciences and Natural Resources Research, Chinese Academy of Sciences, Beijing 100101, China \\ 2 University of Chinese Academy of Sciences, Beijing 10oo49, China
}

Citation: Fu G, Sun W, Yu CQ, et al. (2015) Clipping alters the response of biomass production to experimental warming: a case study in an alpine meadow on the Tibetan Plateau, China. Journal of Mountain Science 12(4). DOI: 10.1007/s11629014-3035-Z

(C) Science Press and Institute of Mountain Hazards and Environment, CAS and Springer-Verlag Berlin Heidelberg 2015

\begin{abstract}
Predicting how human activity will influence the response of alpine grasslands to future warming has many uncertainties. In this study, a field experiment with controlled warming and clipping was conducted in an alpine meadow at three elevations (4313 m, $4513 \mathrm{~m}$ and $4693 \mathrm{~m}$ ) in Northern Tibet to test the hypothesis that clipping would alter warming effect on biomass production. Open top chambers (OTCs) were used to increase temperature since July, 2008 and the OTCs increased air temperature by approximately $0.9^{\circ} \mathrm{C} \sim 1.8^{\circ} \mathrm{C}$ during the growing in 2012. Clipping was conducted three times one year during growing season and the aboveground parts of all live plants were clipped to approximately $0.01 \mathrm{~m}$ in height using scissors since 2009. Gross primary production (GPP) was calculated from the Moderate-
\end{abstract}

Received: 17 June 2014

Accepted: 13 November 2014
Resolution Imaging Spectroradiometer GPP algorithm and aboveground plant production was estimated using the surface-measured normalized difference vegetation index in 2012. Warming decreased the GPP, aboveground biomass (AGB) and aboveground net primary production (ANPP) at all three elevations when clipping was not applied. In contrast, warming increased AGB at all three elevations, GPP at the two lower elevations and ANPP at the two higher elevations when clipping was applied. These findings show that clipping reduced the negative effect of warming on GPP, AGB and ANPP, suggesting that clipping may reduce the effect of climate warming on GPP, AGB and ANPP in alpine meadows on the Tibetan Plateau, and therefore, may be a viable strategy for mitigating the effects of climate change on grazing and animal husbandry on the Tibetan Plateau. 
Keywords: Clipping; Gross primary production; Open top chamber; Warming; Alpine Meadow; Tibetan Plateau

\section{Introduction}

Alpine ecosystems generally accumulate large amounts of carbon (C) under their low temperature conditions ( $\mathrm{Ni}$ 2002; Moriyama et al. 2013), making them highly sensitive to climate change ( $\mathrm{Fu}$ et al. 2012b; Zhao et al. 2012). The Tibetan Plateau, sometimes known as "the Third Pole of the Earth", covers $\sim 2.5$ million $\mathrm{km}^{2}$ and about one-third of this area is alpine meadows, which are vital pasturelands (Cao et al. 2004; Fu et al. 2012c; Shen et al. 2014). The global surface temperature is predicted to increase by $1.0^{\circ} \mathrm{C} \sim 3.7^{\circ} \mathrm{C}$ by the end of this century and the Tibetan Plateau is one of the most sensitive regions to climatic change (IPCC 2013; Fu et al. 2015). Therefore, it is very important to understand how climatic warming and human activity affects $\mathrm{C}$ cycling in the alpine meadows of the Tibetan Plateau.

Gross primary production (GPP), aboveground biomass (AGB) and aboveground net primary production (ANPP) are three primary components of the $\mathrm{C}$ cycle in the alpine meadow ecosystem, which is a system highly sensitive to climatic change that could also have significant feedbacks to global climate change (Yang et al. 2009; Fu et al. 2012a). Understanding the responses of this system to warming and clipping is crucial for predicting changes in $\mathrm{C}$ cycling with global climate change. However, the responses of GPP, AGB and ANPP to warming (De Boeck et al. 2007; Wu et al. 2011; Jiang et al. 2012; Wang et al. 2012, 2013) and clipping (Wan and Luo 2003; Klein et al. 2007) have been inconsistent with respect to vegetation types and initial climatic conditions.

Although several warming experiments have been performed in alpine meadows on the Tibetan Plateau, the responses of plant biomass/ productivity to warming have been inconsistent (Klein et al. 2007; Wang et al. 2012; Fu et al. 2013b). The different responses of plant productivity to warming could be related to different warming patterns (Wang et al. 2012). However, Klein et al. (2007) and Wang et al. (2012) showed contradictory results for the response of
ANPP to grazing in the same alpine meadow with a mean elevation of $3200 \mathrm{~m}$ on the Tibetan Plateau. This was probably attributable to the different grazing patterns and intensities present on this meadow. Only one previous study has investigated the response of GPP to warming in alpine meadows along an elevation gradient on the Tibetan Plateau (Fu et al. 2013b) and no previous studies have described the response of GPP to clipping in this situation, especially in elevation gradients $>4300$ m. Therefore, how climate change affects plant productivity and how clipping influences the warming effects on plant productivity in alpine meadows on the Tibetan Plateau remains unclear and requires investigation.

In this study, a controlled warming and clipping experiment was conducted in an alpine meadow at three elevations ( $4313 \mathrm{~m}, 4513 \mathrm{~m}$ and $4693 \mathrm{~m}$ ) in Northern Tibet. Previous studies have showed that grazing or clipping decreases the effects of warming on ANPP in an alpine meadow on the Tibetan Plateau (Klein et al. 2007; Wang et al. 2012). Therefore, this study hypothesized that clipping will decrease the response of GPP, AGB and ANPP to warming.

\section{Materials and Methods}

\subsection{Study area}

The study area $\left(30^{\circ} 30^{\prime}-30^{\circ} 32^{\prime} \mathrm{N}, 91^{\circ} \mathrm{O} 3^{\prime}-\right.$ $\left.91^{\circ} \mathrm{O} 4^{\prime} \mathrm{E}\right)$ was located at the Damxung Grassland Observation Station in the Tibet Autonomous Region of China (Fu et al. 2013a). The mean annual air temperature is $1.3^{\circ} \mathrm{C}$ and the mean annual precipitation is $\sim 476.8 \mathrm{~mm}$ (Fu et al. 2013a). The soil texture is sandy loam and the soil layer is $0.5^{-}$ $0.7 \mathrm{~m}$ thick, with $0.3 \% \sim 11.2 \%$ organic matter, $0.03 \% \sim 0.49 \%$ total $\mathrm{N}$ and $\mathrm{pH} 6.0 \sim 6.7$ (Fu et al. 2012c). The typical vegetation type in the study area is Kobresia-dominated alpine meadow (Fu et al. 2012b).

\subsection{Experimental design}

The field experiment was set up in three alpine meadow sites located at a low (4313 m), mid (4513 $\mathrm{m})$ and high $(4693 \mathrm{~m})$ elevation. The field experiment was based on a complete two-factor 
design (warming and clipping) with three replicates of four treatments: no warming and no clipping (NW+NCL), warming and no clipping $(\mathrm{W}+\mathrm{NCL})$, clipping and no warming $(\mathrm{CL}+\mathrm{NW})$, warming plus clipping $(\mathrm{W}+\mathrm{CL})$ at each elevation, making a total of 36 experimental plots. In July 2008, six open top chambers (OTCs) were randomly installed and left in place year round at each elevation to enhance the temperature for the warmed plots (W+NCL and W+CL) (Marion et al. 1997). The OTCs were $1.45 \mathrm{~m} \times 1.00 \mathrm{~m} \times 0.40 \mathrm{~m}$ (Fu et al. 2013a; Yu et al. 2014). There was one unwarmed plot in the vicinity of each OTC. Clipping was conducted three times a year (generally in June, July and September) for the two clipped treatments (CL+NW and $\mathrm{W}+\mathrm{CL})$ since 2009. All the aboveground parts of live plants were clipped to approximately $0.01 \mathrm{~m}$ in height using scissors. All the clipped plant materials were removed, oven-dried at $65^{\circ} \mathrm{C}$ for $48 \mathrm{~h}$ and weighted.

Soil temperature (5 cm, TMB-Moo6), soil water content (SWC) (10 cm, SMC-Moo5), air temperature and relative humidity $(15 \mathrm{~cm}$, THBMoo8) were continuously auto-monitored by data loggers (HOBO weather station, Onset Computer, Bourne, MA, USA). Vapor pressure deficit (VPD) was the difference between saturation and actual vapor pressures, which was calculated using the surface measured air temperate and relative humidity (Fu et al. 2012a). Experimental warming increased daily $T_{a}$ by $1.08^{\circ} \mathrm{C}, 1.81^{\circ} \mathrm{C}$ and $0.94^{\circ} \mathrm{C}$ and increased daily VPD by $0.05,0.05$ and 0.03 $\mathrm{kPa}$ at the low, mid and high elevations, respectively from June to September 2012 (Fu et al. 2013b). High VPD can result in stomatal closure and, in turn, affect plant photosynthesis. Warminginduced increases in VPD can aggravate this effect. In contrast, clipping has been found to have no significant effects on these environmental factors (Fu et al. 2013a).

\subsection{Normalized difference vegetation index}

A Tetracam Agricultural Digital Camera (ADC, Tetracam Inc., Chatsworth, CA, USA) was used to take photographs in a $0.5 \mathrm{~m} \times 0.5 \mathrm{~m}$ subplot in the center of each plot from late June to September 2012. The camera has green $(520 \sim 600 \mathrm{~nm})$, red $(630-690 \mathrm{~nm})$ and near-infrared $(760 \sim 900 \mathrm{~nm})$ bands and can produce $2048 \times 1536$ pixels with an
8.0 mm lens (Fu et al. 2013b). The lens of the ADC was parallel to the ground at a height of $\sim 1.0 \mathrm{~m}$ to limit variations in spatial resolution and field of view (Fu et al. 2013b). The field of view and spatial resolution were $\sim 0.8 \mathrm{~m} \times 0.6 \mathrm{~m}$ and $0.4 \mathrm{~mm}$, respectively. Calibration photographs of a white Teflon plate provided by the Tetracam manufacturer were taken before and after each batch of the target photographs and when the light condition changed remarkably. All target photographs were processed using PixelWrench2 software (included with the ADC) to obtain the normalized difference vegetation index (NDVI) and the calibration parameters from photographs of the white Teflon calibration plate (Fu et al. 2013b).

\subsection{GPP algorithm}

The GPP was calculated from the ModerateResolution Imaging Spectroradiometer (MODIS) GPP algorithm. The GPP algorithm has been validated by a previous study ( $\mathrm{Fu}$ et al. 2012a). Moreover, Fu et al. (2013b) quantified the effect of short-term $(<3$ year) experimental warming on GPP in alpine meadows on the Tibetan Plateau.

The MODIS GPP algorithm is based on a light use efficiency (LUE) approach (Reichstein et al. 2007). Absorbed photosynthetically active radiation (APAR) by the plant canopy and LUE

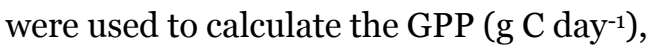

$$
G P P=L U E \times A P A R
$$

LUE is estimated as

$$
L U E=L U E_{\max } \times T_{\text {a min _scalar }} \times V P D_{\text {-scalar }}
$$

where $L U E_{\max }$ refers to the ecosystem apparent quantum yield or maximum light use efficiency ( $\mathrm{g}$ $\left.\mathrm{C} \mathrm{MJ}^{-1}\right)$. The $L U E_{\max }$ was set to be $0.81 \mathrm{~g} \mathrm{C} \mathrm{MJ}^{-1}(\mathrm{Fu}$ et al. 2012a). The two attenuation scalars, $T_{\text {amin_scalar }}$ and $V P D_{\text {_scalar }}$, were calculated using the daily minimum $T_{a}\left(T_{a m i n}\right)$ and daytime average VPD, respectively (Reichstein et al. 2007).

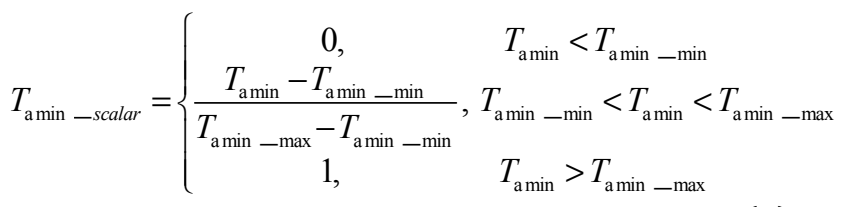




$$
V P D_{- \text {scalar }}=\left\{\begin{array}{cc}
0, & V P D>V P D_{\max } \\
\frac{V P D_{\max }-V P D}{V P D_{\max }-V P D_{\min }}, & V P D_{\min }<V P D<V P D_{\max } \\
1, & V P D<V P D_{\min }
\end{array}\right.
$$

APAR was calculated as:

$$
A P A R=P A R \times F P A R
$$

where FPAR was the fraction of plant canopy APAR and was calculated using the observed NDVI values (Fu et al. 2013b).

$$
\begin{gathered}
F P A R=\frac{F P A R_{N D V I}+F P A R_{S R}}{2} \\
F P A R_{N D V I}=\frac{\left(N D V I-N D V I_{\min }\right)\left(F P A R_{\max }-F P A R_{\min }\right)}{N D V I_{\max }-N D V I_{\min }}+F P A R_{\min } \\
F P A R_{S R}=\frac{\left(S R-S R_{\min }\right)\left(F P A R_{\max }-F P A R_{\min }\right)}{S R_{\max }-S R_{\min }}+F P A R_{\min } \\
S R=\frac{1+N D V I}{1-N D V I}
\end{gathered}
$$

where $F P A R_{\max }=0.95$ and $F P A R_{\min }=0.001(\mathrm{Fu}$ et al. 2013b).

Other model parameters to calculate GPP can be found in Fu et al. (2013b).

\subsection{AGB and ANPP estimation}

AGB and ANPP were estimated using a nondestructive approach (Fu et al. 2013b). Based on the regression equation ( $\mathrm{AGB}=10.33^{3} \mathrm{e}^{3.28 \mathrm{NDVI}}, R^{2}=$ 0.64, $p<0.001, \mathrm{n}=135$ ) between AGB and NDVI warming and clipping as the between subject factors and sampling date as the within subject factor was conducted for GPP and AGB (Table 1). A univariate ANOVA was conducted for ANPP at each elevation. Linear regression analyses between GPP, AGB, ANPP, $T_{a}$ and SWC were conducted. All the statistical analyses were performed using SPSS software (version 16.0; SPSS Inc., Chicago, IL).

\section{Results and Discussion}

The GPP and AGB showed similar seasonal dynamics along the three elevations regardless of the warming and clipping treatments (Figure 1). The significant seasonal changes of GPP and AGB (Table 1) were similar to those in previous studies and the average GPP and AGB values (Figure 1) were close to previous observations in alpine meadows on the Tibetan Plateau (Hu et al. 2008; Fu et al. 2013b).

Regardless of clipping effects, warming significantly decreased the average GPP and AGB by $16.0 \%\left(-0.15 \mathrm{~g} \mathrm{C} \mathrm{m}^{-2} \mathrm{~d}^{-1}\right)$ and $11.3 \%\left(-2.95 \mathrm{~g} \mathrm{~m}^{-2}\right)$, respectively, at the low elevation (Table 1). Warming non-significantly reduced GPP by $2.7 \%$ $\left(-0.04 \mathrm{~g} \mathrm{C} \mathrm{m}^{-2} \mathrm{~d}^{-1}\right)$ and AGB by $6.2 \%\left(-2.17 \mathrm{~g} \mathrm{~m}^{-2}\right)$ at the mid elevation and reduced GPP by $6.4 \%$ (-0.10 $\left.\mathrm{g} \mathrm{C} \mathrm{m}^{-2} \mathrm{~d}^{-1}\right)$ and AGB by $2.3 \%\left(-0.98 \mathrm{~g} \mathrm{~m}^{-2}\right)$ at the high elevation irrespective of clipping (Table 1). These results are in line with previous studies which showed that warming significantly or partially reduced GPP and AGB (Fu et al. 2013b).
(Fu et al. 2013b), the AGB was estimated for all treatments and elevations. The maximum AGB during the growing season was treated as the ANPP.

\subsection{Statistical analysis}

At each site a repeated-measures ANOVA with

\begin{tabular}{|c|c|c|c|c|c|c|}
\hline \multirow{2}{*}{ Model } & \multicolumn{3}{|c|}{ AGB } & \multicolumn{3}{|c|}{ GPP } \\
\hline & $4313 \mathrm{~m}$ & $4513 \mathrm{~m}$ & $4693 \mathrm{~m}$ & $4313 \mathrm{~m}$ & $4513 \mathrm{~m}$ & $4693 \mathrm{~m}$ \\
\hline Warming & $9.01^{*}$ & 0.91 & 0.26 & $12.27^{* *}$ & 0.20 & 2.51 \\
\hline Clipping & $37.14^{* * *}$ & $34.99^{* * *}$ & $27.84^{* * *}$ & $40.59^{* * *}$ & $33.39^{* * *}$ & $28.51^{* * *}$ \\
\hline Date & $58.01^{* * *}$ & $81.01^{* * *}$ & $115.01^{* * *}$ & $187 \cdot 30^{* * *}$ & $364.01^{* * *}$ & $392.03^{* * *}$ \\
\hline $\mathrm{W} \times \mathrm{CL}$ & $12.48^{* *}$ & 3.25 & 0.47 & $14.33^{* *}$ & $6.20^{*}$ & 1.52 \\
\hline $\mathrm{W} \times \mathrm{D}$ & $3 \cdot 36$ & 0.71 & $9.23^{* * *}$ & $5.04^{*}$ & 1.25 & $9.37^{* * *}$ \\
\hline$C L \times D$ & $9.55^{* *}$ & $11.92^{* * *}$ & $10.95^{* * *}$ & $12.08^{* * *}$ & $19.5^{2 * * *}$ & $15.22^{* * *}$ \\
\hline $\mathrm{W} \times \mathrm{CL} \times \mathrm{D}$ & 1.86 & 2.06 & 0.62 & 2.31 & 1.63 & 1.43 \\
\hline
\end{tabular}
experimental
Table 1 Repeated measures ANOVA indicating $F$ values for the main and interactive effects of warming (W), clipping (CL) and measuring date (D) on aboveground biomass (AGB, $\mathrm{g} \mathrm{m}^{-2}$ ) and gross primary production (GPP, $\mathrm{g}$ C $\mathbf{m}^{-2} \mathbf{d}^{-1}$ ) in an alpine meadow at different elevations in Northern Tibet

Notes: ${ }^{*}{ }^{* *}$ and ${ }^{* * *}$ represent $p<0.05, p<0.01$ and $p<0.001$, respectively 


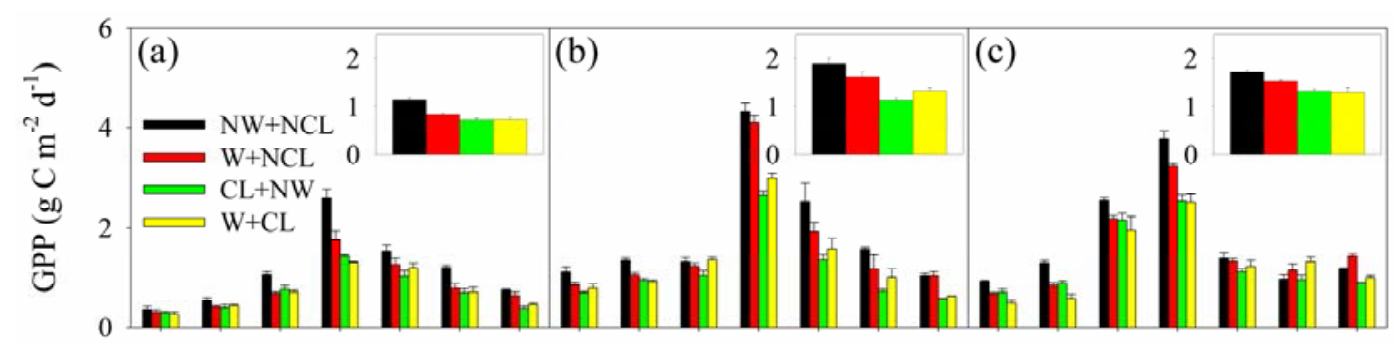

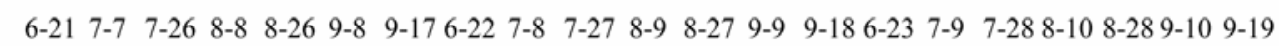

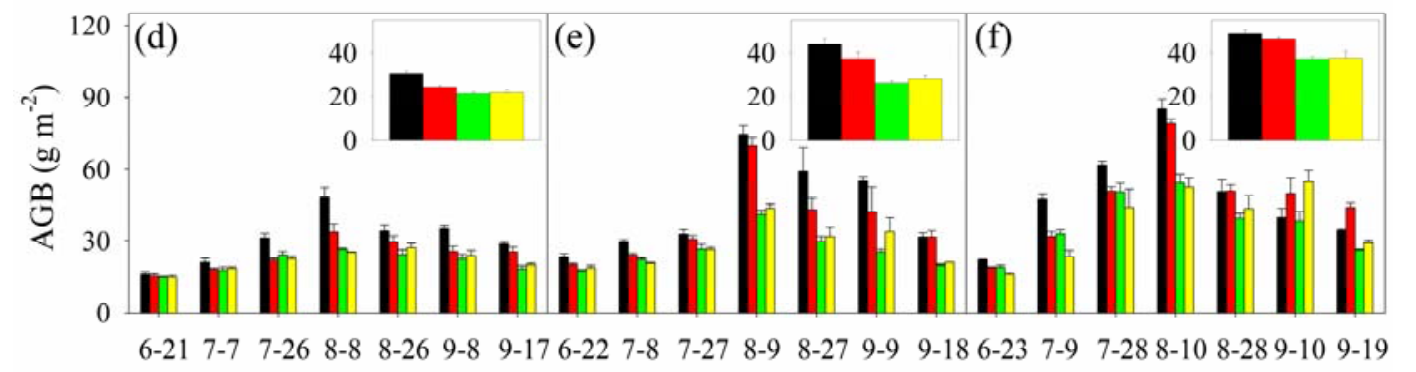

Date (Month-Day)

Figure 1 Seasonal variation of gross primary production (GPP, $\mathrm{g} \mathrm{C} \mathrm{m}^{-2} \mathrm{~d}^{-1}$ ) and aboveground biomass $\left(\mathrm{AGB}, \mathrm{g} \mathrm{m}^{-2}\right.$ ) under controlled warming and clipping conditions in an alpine meadow at elevations of $4313 \mathrm{~m}(\mathrm{a}, \mathrm{d}), 4513 \mathrm{~m}$ (b,e) and $4693 \mathrm{~m}(\mathrm{c}, \mathrm{f})$ in Northern Tibet. Error bars represent standard errors $(n=3)$. NW+NCL: no warming and no clipping, W+NCL: warming and no clipping, $\mathrm{CL}+\mathrm{NW}$ : clipping and no warming, W+CL: warming and clipping.

In addition, previous studies have found that warming decreased ecosystem respiration and soil microbial biomass in the same alpine meadow, although not all these declines were significant $(\mathrm{Fu}$ et al. 2012b, 2013a). These findings imply that warming depressed some fluxes and pools of the $\mathrm{C}$ cycle in this alpine meadow. Warming tended to decrease ANPP at the lower elevations, but tended to increase ANPP at the high elevation regardless of clipping. This finding was not in line with previous studies which showed that warming significantly reduced or increased ANPP in an alpine meadow on the Tibetan Plateau (Klein et al. 2007; Wang et al. 2012). These results implied that the response of GPP, AGB and ANPP to warming most likely varied in each alpine meadow on the Tibetan Plateau.

In the same alpine meadow, a previous study implied that the declines of GPP and AGB under warming were simultaneously suppressed by experimental warming-induced soil drying and temperature increase (Fu et al. 2013b). In line with Fu et al. (2013b), this study found that GPP, AGB and ANPP increased with increasing SWC, and decreased with increasing $T_{a}$ (Figure 2). Moreover, the declines of GPP, AGB and ANPP under warming may be also related to changes in the soil microbial biomass because soil microbial activity may affect soil nitrogen (N) availability. Plant productivity increases with increasing soil $\mathrm{N}$ availability or inorganic $\mathrm{N}$ in alpine meadows on the Tibetan Plateau (Rui et al. 2011; Zong et al. 2013; Fu et al. 2014; Yu et al. 2014). Zong et al. (2013) showed that warming significantly reduced the net $\mathrm{N}$ mineralization rate at low elevations. Similarly, Yu et al. (2014) found that warming significantly decreased soil inorganic $\mathrm{N}$ at low and mid elevations. The reduction in soil $\mathrm{N}$ availability may reduce plant photosynthesis and biomass accumulation in the alpine meadows of this study. In addition, the different effects of warming on GPP and AGB may be attributed to different temperature and moisture conditions ( $\mathrm{Fu}$ et al. 2013b), changes in soil microbial biomass (Fu et al. 2012b) and changes in inorganic N (Yu et al. 2014) at the three elevations. The experimental warminginduced warming and drying might have caused a deviation from the optimum conditions, and the level of this deviation decreased with increasing elevation ( $\mathrm{Fu}$ et al. 2013b). The experimental warming-induced decrease in soil microbial biomass and inorganic $\mathrm{N}$ content also declined with increasing elevation ( $\mathrm{Fu}$ et al. 2012b; Yu et al. 2014). Experimental warming-induced changes in 

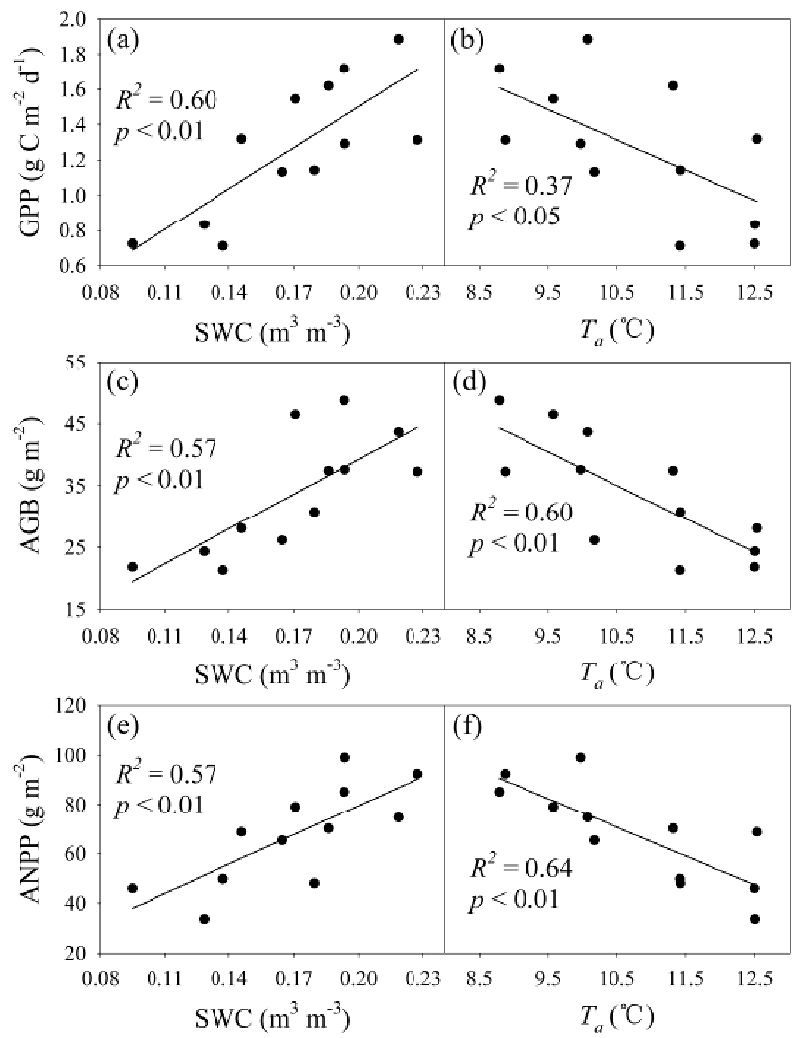

Figure 2 Relationships between growing-season average gross primary production (GPP, $\mathrm{g} \mathrm{C} \mathrm{m}^{-2} \mathrm{~d}^{-1}$ ), aboveground biomass (AGB, $\mathrm{g} \mathrm{m}^{-2}$ ), aboveground net primary production (ANPP, $\mathrm{g} \mathrm{m}^{-2}$ ) and soil water content (SWC, $\left.\mathrm{m}^{3} \mathrm{~m}^{-3}\right)(\mathrm{a}, \mathrm{c}, \mathrm{e})$ and between growing-season average GPP, AGB, ANPP and air temperature $\left(T_{a},{ }^{\circ} \mathrm{C}\right)(\mathrm{b}, \mathrm{d}, \mathrm{f})$ across elevation and warming and clipping treatments in an alpine meadow in Northern Tibet.

GPP, AGB and ANPP tended to increase with that of SWC and $T_{a}$ (Figure 3).

Regardless of warming effects, clipping significantly reduced GPP by $27.3 \%\left(-0.27 \mathrm{~g} \mathrm{C} \mathrm{m}^{-2}\right.$ $\left.\mathrm{d}^{-1}\right), 30.0 \%\left(-0.53 \mathrm{~g} \mathrm{C} \mathrm{m}^{-2} \mathrm{~d}^{-1}\right)$ and 20.1\% (-0.33 g C $\left.\mathrm{m}^{-2} \mathrm{~d}^{-1}\right)$ and AGB by $21.8 \%\left(-6.00 \mathrm{~g} \mathrm{C} \mathrm{m}^{-2}\right), 33.2 \%$ $\left(-13.46 \mathrm{~g} \mathrm{C} \mathrm{m}^{-2}\right)$ and $21.3 \%\left(-10.15 \mathrm{~g} \mathrm{C} \mathrm{m}^{-2}\right)$ at the low, mid and high elevations, respectively (Table 1 , Figure 1). This finding was in line with previous studies (Wan and Luo 2003; Lin et al. 2011). Considering the non-significant changes in temperature and water availability conditions caused by clipping (Fu et al. 2013a), the depression effect of clipping on GPP may be mainly attributed to the effect of FPAR. The removal of plant photosynthesis organs by clipping can explain the decreases of GPP, which, in turn, resulted in AGB reductions. The previous study showed that grazing
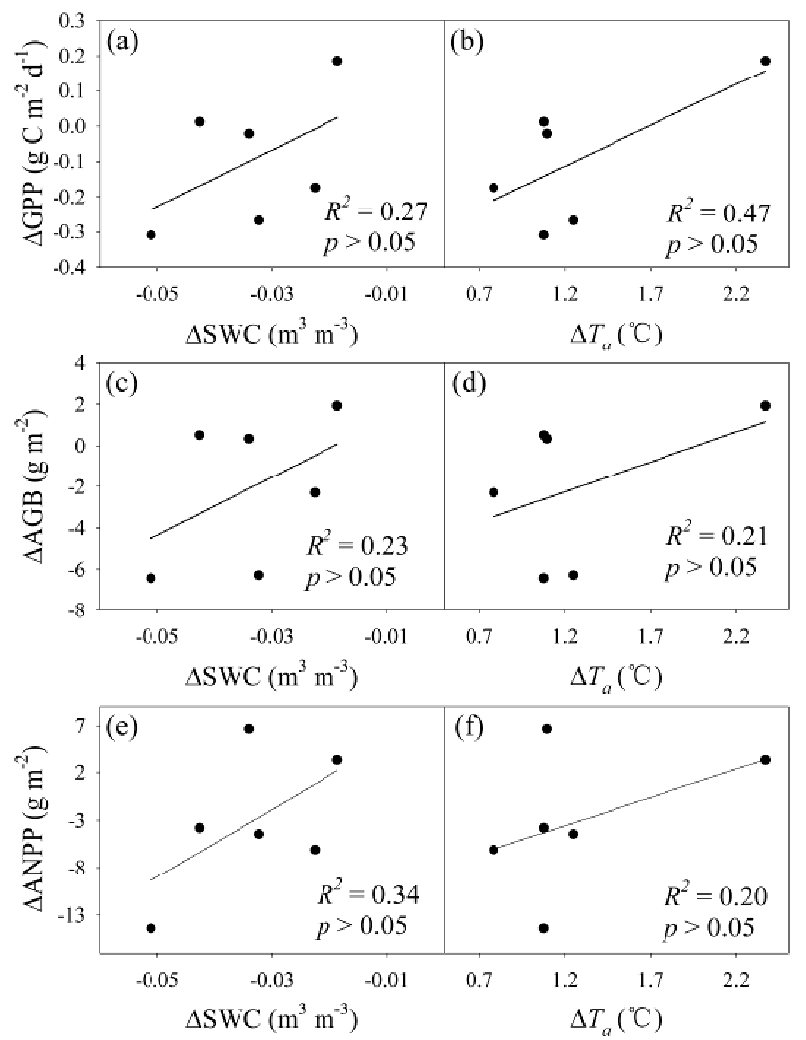

Figure 3 Relationships between warming-induced changes in growing-season average gross primary production (GPP, $\mathrm{g} \mathrm{C} \mathrm{m}^{-2} \mathrm{~d}^{-1}$ ), aboveground biomass (AGB, $\mathrm{g} \mathrm{m}^{-2}$ ), aboveground net primary production (ANPP, $\mathrm{g} \mathrm{m}^{-2}$ ) and soil water content (SWC, $\left.\mathrm{m}^{3} \mathrm{~m}^{-3}\right)$ (a, c, e) and between warming-induced changes in growing-season average GPP, AGB, ANPP and air temperature $\left(T_{a},{ }^{\circ} \mathrm{C}\right)(\mathrm{b}, \mathrm{d}, \mathrm{f})$ across elevation and warming and clipping treatments in an alpine meadow in Northern Tibet.

significantly decreased soil inorganic $\mathrm{N}$ content at the two lower elevations (Fu et al. 2014) and soil microbial biomass $\mathrm{N}$ at the low and high elevations (Fu et al. 2012c). These findings implied that the negative effect of clipping on GPP and AGB may be also attributed to the reduction of soil $\mathrm{N}$ availability probably caused by clipping. However, further studies are necessary to further investigate the probable differences between clipping and grazing. The main effects of clipping on ANPP were nonsignificant at the three elevations. Likewise, Klein et al. (2007) demonstrated that clipping increased ANPP, but these increases were non-significant. Wang et al. (2012) indicated that grazing did not affect ANPP in 2006, 2009 or 2010.

Without clipping, warming significantly decreased GPP by $27 \%\left(-0.31 \mathrm{~g} \mathrm{C} \mathrm{m}^{-2} \mathrm{~d}^{-1}\right)$ and AGB by $20.9 \%\left(-6.43 \mathrm{~g} \mathrm{C} \mathrm{m}^{-2}\right)$ at the low elevation, and 
GPP by $10.1 \%\left(-0.17 \mathrm{~g} \mathrm{C} \mathrm{m}^{-2} \mathrm{~d}^{-1}\right)$ at the high elevation. It also had fractional negative effects on GPP (-14.2\%, -0.27 $\left.\mathrm{g} \mathrm{C} \mathrm{m}^{-2} \mathrm{~d}^{-1}\right)$ and AGB (-14.4\%, $\left.-6.28 \mathrm{~g} \mathrm{C} \mathrm{m}^{-2}\right)$ at the mid elevation and AGB $(-4.7 \%$,

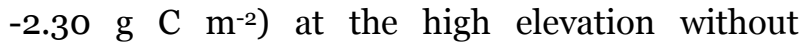
clipping. In contrast, with clipping, warming nonsignificantly increased AGB by $2.5 \%\left(+0.52 \mathrm{~g} \mathrm{C} \mathrm{m}^{-2}\right)$, 7.4\% (+ $\left.1.93 \mathrm{~g} \mathrm{C} \mathrm{m}^{-2}\right)$ and $0.9 \%\left(+0.34 \mathrm{~g} \mathrm{C} \mathrm{m}^{-2}\right)$ at the low, mid and high elevations, respectively, and non-significantly increased GPP at the two lower elevations (low: $+1.7 \%$, +0.01 $\mathrm{g} \mathrm{C} \mathrm{m}^{-2} \mathrm{~d}^{-1}$; mid: $+16.4 \%$, +0.19 $\mathrm{g} \mathrm{C} \mathrm{m}^{-2} \mathrm{~d}^{-1}$ ), but non-significantly reduced GPP at the high elevation by $1.6 \%$ (-0.02 $\mathrm{g}$ $\mathrm{C} \mathrm{m}^{-2} \mathrm{~d}^{-1}$ ) with clipping. Warming non-significantly decreased ANPP by 29.89\% (-14.38 $\left.\mathrm{g} \mathrm{C} \mathrm{m}^{-2}\right), 5.96 \%$ $\left(-4.45 \mathrm{~g} \mathrm{C} \mathrm{m}^{-2}\right)$ and $7.16 \%\left(-6.09 \mathrm{~g} \mathrm{C} \mathrm{m}^{-2}\right)$ at the low, mid and high elevation, respectively, without clipping. With clipping, warming non-significantly decreased ANPP by $7.60 \%\left(-3.79 \mathrm{~g} \mathrm{C} \mathrm{m}^{-2}\right)$ at the low elevation, but non-significantly increased ANPP by $5.07 \%\left(+3.32 \mathrm{~g} \mathrm{C} \mathrm{m}^{-2}\right)$ and $7.23 \%(+6.68 \mathrm{~g}$ $\mathrm{C} \mathrm{m}^{-2}$ ) at the mid and high elevation, respectively. In addition, there were significant interactive effects of warming and clipping on AGB at the low elevation and GPP at the low and mid elevations (Table 1). These findings suggested that clipping reduced the negative effect of warming on GPP, AGB and ANPP, which was in line with our study hypothesis and results of previous studies (Klein et al. 2007). Similarly, Wang et al. (2012) found that

\section{References}

Cao GM, Tang YH, Mo WH, et al. (2004) Grazing intensity alters soil respiration in an alpine meadow on the Tibetan plateau. Soil Biology \& Biochemistry 36: 237-243. DOI: 10.1016/j.soilbio.2003.09.010

De Boeck HJ, Lemmens C, Vicca S, et al. (2007) How do climate warming and species richness affect $\mathrm{CO}_{2}$ fluxes in experimental grasslands? New Phytologist 175: 512-522.

Fu G, Shen Z, Zhang X, et al. (2012a) Calibration of MODISbased gross primary production over an alpine meadow on the Tibetan Plateau. Canadian Journal of Remote Sensing 38: 157-168.

Fu G, Shen Z, Zhang X, et al. (2013a) Response of ecosystem respiration to experimental warming and clipping at daily time scale in an alpine meadow of Tibet. Journal of Mountain Science 10: 455-463. DOI: 10.1007/s11629-013-2360-y

Fu G, Shen Z, Zhang X, Zhou Y (2012b) Response of soil microbial biomass to short-term experimental warming in alpine meadow on the Tibetan Plateau. Applied Soil Ecology 61: 158-160.

Fu G, Shen Z, Zhang X, et al. (2012c) Response of microbial the positive effect of warming on ANPP was reduced by sheep grazing in an alpine meadow on the Tibetan Plateau. Therefore, clipping or grazing can reduce the effects of warming on plant productivity in alpine meadows on the Tibetan Plateau.

\section{Conclusions}

Our results show that clipping reduced the negative effect of warming on GPP, AGB and ANPP in an alpine meadow in Northern Tibet. Therefore, clipping may be a viable strategy for mitigating the effects of climate change on grazing and animal husbandry on the Tibetan Plateau.

\section{Acknowledgements}

This work was funded by the National Natural Science Foundation of China (Grant No. 41171084) and the Natural Science Foundation of Tibet Autonomous Region (Response of species richness and aboveground biomass to warming in the alpine meadows of Tibet). We thank the anonymous reviewers for their insightful and valuable comments, which have greatly improved the quality of this manuscript. biomass to grazing in an alpine meadow along an elevation gradient on the Tibetan Plateau. European Journal of Soil Biology 52: 27-29. DOI: 10.1016/j.ejsobi.2012.05.004

Fu G, Shen ZX, Sun W, et al. (2015) A meta-analysis of the effects of experimental warming on plant physiology and growth on the Tibetan Plateau. Journal of Plant Growth Regulation 34: 57-65. DOI: 10.1007/so0344-014-9442-O

Fu G, Zhang X, Zhang Y, et al. (2013b) Experimental warming does not enhance gross primary production and aboveground biomass in the alpine meadow of Tibet. Journal of Applied Remote Sensing 7(1). DOI: 10.1117/1111.jrs.1117. 073505.

Fu G, Zhang XZ, Yu CQ, et al. (2014) Response of soil respiration to grazing in an alpine meadow at three elevations in Tibet. Scientific World Journal. DOI: 10.1155/2014/265142.

Hu ZM, Yu GR, Fu YL, et al. (2008) Effects of vegetation control on ecosystem water use efficiency within and among four grassland ecosystems in China. Global Change Biology 14: 1609-1619. DOI: 10.1111/j.1365-2486.2008.01582.x

IPCC (2013) Summary for Policymakers. In: Stocker TF, Qin D, 
Plattner GK, et al. (eds.), Climate Change 2013: The Physical Science Basis. Contribution of Working Group I to the Fifth Assessment Report of the Intergovernmental Panel on Climate Change. Cambridge University Press, Cambridge, United Kingdom and New York, NY, USA. pp 20-23.

Jiang L, Guo R, Zhu TC, et al. (2012) Water- and plant-mediated responses of ecosystem carbon fluxes to warming and nitrogen addition on the Songnen grassland in Northeast China. PLoS ONE 7(9). DOI: 10.1371/journal.pone.0045205.

Klein JA, Harte J, Zhao XQ (2007) Experimental warming, not grazing, decreases rangeland quality on the Tibetan Plateau. Ecological Applications 17: 541-557.

Lin XW, Zhang ZH, Wang SP, et al. (2011) Response of ecosystem respiration to warming and grazing during the growing seasons in the alpine meadow on the Tibetan plateau. Agricultural and Forest Meteorology 151: 792-802. DOI: 10.1016/j.agrformet.2011.01.009

Marion GM, Henry GHR, Freckman DW, et al. (1997) Open-top designs for manipulating field temperature in high-latitude ecosystems. Global Change Biology 3: 20-32.

Moriyama A, Yonemura S, Kawashima S, et al. (2013) Environmental indicators for estimating the potential soil respiration rate in alpine zone. Ecological Indicators 32: 245252. DOI: 10.1016/j.ecolind.2013.03.032

$\mathrm{Ni} \mathrm{J}$ (2002) Carbon storage in grasslands of China. Journal of Arid Environments 50: 205-218.

Reichstein M, Ciais P, Papale D, et al. (2007) Reduction of ecosystem productivity and respiration during the European summer 2003 climate anomaly: a joint flux tower, remote sensing and modelling analysis. Global Change Biology 13: 634-651. DOI: 10.1111/j.1365-2486.2006.01224.x

Rui YC, Wang SP, Xu ZH, et al. (2011) Warming and grazing affect soil labile carbon and nitrogen pools differently in an alpine meadow of the Qinghai-Tibet Plateau in China. Journal of Soils and Sediments 11: 903-914. DOI: 10.1007/s11368011-0388-6

Shen Z, Fu G, Yu C, et al. (2014) Relationship between the growing season maximum enhanced vegetation index and climatic factors on the Tibetan Plateau. Remote Sensing 6: 6765-6789. DOI: $10.3390 /$ rs6o86765

Wan SQ, Luo YQ (2003) Substrate regulation of soil respiration in a tallgrass prairie: Results of a clipping and shading experiment. Global Biogeochemical Cycles 17: 1054. DOI: 1010.1029/2002GBoo1971

Wang SP, Duan JC, Xu GP, et al. (2012) Effects of warming and grazing on soil $\mathrm{N}$ availability, species composition, and ANPP in an alpine meadow. Ecology 93: 2365-2376.

Wang Z, Luo TX, Li RC, et al. (2013) Causes for the unimodal pattern of biomass and productivity in alpine grasslands along a large altitudinal gradient in semi-arid regions. Journal of Vegetation Science 24: 189-201. DOI: 10.1111/ j.1654-1103.2012.01442.x

Wu ZT, Koch GW, Dijkstra P, et al. (2011) Responses of ecosystem carbon cycling to climate change treatments along an elevation gradient. Ecosystems 14: 1066-1080. DOI: 10.1007/s10021-011-9464-4

Yang YH, Fang JY, Ji CJ, Han WX (2009) Above- and belowground biomass allocation in Tibetan grasslands. Journal of Vegetation Science 20: 177-184. DOI: 10.1111/ j.1654-1103.2009.05566.x

Yu CQ, Shen ZX, Zhang XZ, et al. (2014) Response of soil C and $\mathrm{N}$, dissolved organic $\mathrm{C}$ and $\mathrm{N}$, and inorganic $\mathrm{N}$ to short-term experimental warming in an alpine meadow on the Tibetan Plateau. Scientific World Journal. DOI: 10.1155/2014/152576.

Zhao WL, Qi JG, Sun GJ, Li FM (2012) Spatial patterns of top soil carbon sensitivity to climate variables in northern Chinese grasslands. Acta Agriculturae Scandinavica Section B-Soil and Plant Science 62: 720-731. DOI: 10.1080/ 09064710.2012.698641

Zong N, Shi PL, Jing J, et al. (2013) Responses of ecosystem $\mathrm{CO}_{2}$ fluxes to short-term experimental warming and nitrogen enrichment in an alpine meadow, Northern Tibet Plateau. Scientific World Journal: 415318. DOI: 10.1155/2013/415318 